\section{ARMSTRONG-WHITWORTH TAILLESS GLIDER}

$I^{N}$

NFORMATION has just been released that an experimental glider of the 'Flying Wing' type, known as the A.W.52G., has been in operation since March 1945. It was designed and built in Messrs. Armstrong-Whitworth's works for experiment upon the behaviour of this kind of aireraft in those respects in which only full-scale tests give reliable data, particularly control and stability, without the more conventional tail surfaces. Experience gained upon this will be used possibly for the design of larger tailless machines of multi-engined and jet-propelled types. Flying has been carried out by Mr. C. TurnerHughes, followed by Mr. E. G. Franklin, and the design was due to the firm's chief designer, Mr. J. Lloyd.

The general layout of the machine is a monoplane of broad 'Vee' plan form, the wings having a sweep back on the leading edges of $30^{\circ}$. The wing span is $53 \mathrm{ft} .4 \mathrm{in}$., and the chord is $12 \mathrm{ft} .4 \frac{1}{2} \mathrm{in}$. at the root, with a considerable taper to the tips. Rudders and fins are carried on the wing tips. It is probable that this glider could have been flown without rudders, but knowledge of their behaviour was needed for the design of a larger multi-engined aircraft, that would need them to correct yaw due to failure of one of the engines. The principal control is obtained by a combination of trailing edge flaps and tabs, modified by correctors, controllers, and spoilers, an arrangement of extremely novel type. The construction is of wood, and a smooth and non-varying profile form is obtained by making the skin of 'Plymax', which is plywood with light alloy sheet bonded together.

A test glide is made by towing the machine to about $12,000 \mathrm{ft}$. altitude and releasing it. The resulting glide to earth takes about twenty-five minutes, and most of the observations are taken by recording instruments and photographic records taken with specially designed cinematograph cameras.

It is probable that whatever the results work out to be for propeller-driven machines and to-day's speeds, wings with a pronounced sweepback will be a necessity with jet propulsion at supersonic speeds, to delay the onset of compressibility. The wing tips, being so far back, may conceivably be able to carry the directional control surfaces efficiently, and the drag and weight of the conventional tail and its supporting girder avoided. The absence of a tail may also help the closer grouping of multiple-jet power units nearer the centre line of the aircraft, which will reduce the offset pull due to the failure of one of them. The close grouping of the engines is limited nowadays by propeller diameter; but this trouble is avoided with jet propulsion.

\section{TRANSFORMER OILS}

A GENERAL discussion on transformer oil, organised by Mr. E. A. Evans, vice-president of the Institute of Petroleum, was held at the Institution of Electrical Engineers on April 9.

P.W. L. Gossling and A. C. Michie, in presenting the contribution of the British Electrical and Allied Industries Research Association to international research on transformer oils, pointed out that so long ago as 1926 the Advisory Committee of the International Electrotechnical Commission arranged that comparative tests on samples of identical oils should be carried out by the various standard national methods. So it was apparent in those days that a serious effort was being made to develop an international standard method for the examination of insulating oils. In 1930 the Committee appointed delegates to study the factors influencing the oxida. tion of oils, because it was clear that the methods of test were handicapped by insufficient knowledge of the subject.

The British Standard Specification 148 was a bold attempt to formulate the requirements of transformer oils for the British market. That specification has been subject to revision, but in principle it remains substantially as it originally stood. Of course it had critics. So, in 1935 the International Electrotechnical Commission submitted a questionnaire to the international committees inquiring for the principal causes of trouble in transformers. The British reply was that, prior to the introduction of B.S.148, breakdowns were mainly attributed to sludge; but since its introduction this type of breakdown had been practically eliminated. The replies from other countries indicated that sludge was the most troublesome.

About this time Class A oil, which is virtually a technical white oil, was beginning to lose some of its popularity, due to the alleged acid formation and the risk of corrosion. On the Continent of Europe this type of oil had never been really popular; but the different points of view cannot be wholly separated from the designs of the respective transformers. In Great Britain, varnished windings were much used, whereas in Switzerland bare cotton was exposed to the acid in the oil and was therefore subject to deterioration by generated acidic bodies.

During the last year or two, there have been murmurs about the transformer oil which was available. It was therefore considered prudent to make as complete an investigation as possible so that the postwar programme could be undertaken with the maximum of considered opinions.

J. Wood-Mallock presented a paper on "Some Developments in the Refining of Transformer Oils". He stated that sulphuric acid is still used in refining electrical oils. By increasing the treatment with the acid the tendency towards acid production on ageing increases; therefore it is well understood that if an oil is generously treated with sulphuric acid it will have a greater tendency towards acid formation, and possible corrosion. But, when liquid sulphur dioxide is used as a refining agent, an oil is produced with much reduced tendency towards acid formation. This seems to be true, even with an increase in solvent dosage. On the other hand, a reduction in sludging value is obtained by increasing the degree of acid treatment.

In this very well-reasoned paper Wood-Mallock produced evidence that by certain treatment the natural inhibitors are removed and that during refining pro-oxidants can be introduced. In fact, an oil containing 0.0014 per cent ash consisting principally of calcium sulphonate would give a sludge value many times that of an oil from which this material was absent. So refiners are faced with the difficulty of retaining the anti-oxidants and avoiding or removing the pro-oxidants. If it is difficult to evade these two problems, then it is natural to turn to antioxidants.

P. George and A. Robertson, of the Department of Colloid Science, Cambridge, gave "A Review of the Mechanism of the Oxidation of Liquid Hydrocarbons". 
They indicated that oxidation does not occur at the unsaturated bond, according to the long-accepted theory, but at a $\mathrm{C}-\mathrm{H}$ bond. Hydroperoxides are formed and can be isolated in certain cases. After the preliminary formation of a hydroperoxide, the course of the oxidation is governed by its decomposition. There is much evidence that ketones are the key decomposition products from which the more highly oxidized compounds are derived. Hydroperoxide formation in both thermal and catalysed reactions proceeds by a chain mechanism. Whereas the catalysed reactions involve free radicals as the chain carriers, there is some evidence that in the thermal reaction the chain carriers can be free radicals or energy-rich molecules, depending on the particular hydrocarbon which is oxidized. In the uncatalysed oxidation the auto-catalytic increase is due to a hydroperoxide catalyst reaction developing side by side with the thermal oxidation.

It should not be too difficult, now that our know. ledge of oxidation is improving rapidly, to predict the stability to oxidation of a pure hydrocarbon of known structure. Apparently, the oil starts to oxidize almost uncatalysed, and as acids are produced they gradually dissolve away various catalytic metals and so catalytic oxidation proceeds.

Anti-oxidation has long been known, but there is a shyness, or perhaps distrust, towards it among makers of transformer oil.

E. A. Evans stated in his paper that the time is at hand when broad principles must be introduced, studied and applied. Caution can be observed, provided it does not decelerate progress. If oxidation of transformer oil is objectionable, any method by which it can be reduced is worthy of consideration; fear that a method is transitory is insufficient to condemn it. Chemical additives have been introduced and are now standardized in many industries, as well as in certain branches of the petroleum industry, particularly lubricants which are akin to transformer oil. How the petroleum industry is attracted to anti-oxidants is revealed in this paper.

Probably no one is perfectly happy with the many methods which have been suggested for measuring the propensity of an oil to oxidize; but C. H. Barton feels that the sludge test for transformer oils as practised in Great Britain is too unreliable in its present form, and, of course, he gave supporting evidence for his attack.

A. A. Pollitt, in his paper, reviewed the oxidation tests for transformer oil which are practised in other countries and indicated that they possess no general advantage over the British method. This comparison and criticism is a very useful contribution as it emphasizes the difficulties of the problem.

Messrs. Gossling and Romney gave a paper which showed fairly conclusively that even an apparently small difference, such as variation of the water temperature in the condenser, has a profound effect upon the amount of oxidation produced.

Mr. Norris, in the discussion which followed the papers, speaking as a transformer engineer of many years experience, suggested that insufficient attention has been given to the insulating material in a transformer other than oil. $\mathrm{He}$ felt that the insulating varnish has a considerable effect upon the decomposition of the oil. His view appeared to be that if varnish were excluded much of the trouble would be eliminated.

Collected information by the Incorporated Municipal Electrical Association was presented by D. P.
Sayers. This was based upon replies to a questionnaire issued to twenty-two large municipal undertakings, which have some ten thousand transformers in service ranging in size from $5 \mathrm{kVA}$. to $4,000-5,000$ $\mathrm{kVA}$., aggregating in all more than 6 million $\mathrm{kVA}$. It is significant that in less than 2 per cent of the ten thousand transformers has any acid trouble been experienced. More than 90 per cent of the troublesome transformers were filled with Class A oil. The information received as to the effect on the transformer of high acid values in the oil is far from onsistent. The principal effect is on the inside of the lid and tank sides above oil level. Although this occurs with high acid values, instances were given of attack with values less than $1 \mathrm{mgm}$./KOH. In the majority of cases the acid appears to have no direct deleterious effect on the insulating materials or copper windings. When once acidification has started, however, the process continues.

A. G. Ellis confirmed that sludge is not a matter for much anxiety these days. Acid trouble has been practically confined to Class A oil. Neither C. W. Marshall, who is mainly interested in the Class B oils in large transformers, nor L. H. Welch, whose principal concern is small transformers, had any serious criticisms to make about large transformers. Possibly this is mainly due to the great care taken in their maintenance; small transformers should be given more attention.

R. Weaving reminded the meeting that there was trouble fifteen to twenty years ago, but undoubtedly there has been an improvement in the quality of the oil and in the design of transformers, particularly in the elimination of hot spots or, as the chemist would prefer to say, hot zones. Very few transformers are on full load continuously, therefore we should reconsider the subject of temperature, particularly in the testing of oil. The pre-eminence given to acid at the present time may be one of those cycles of fashion which occur; on the other hand, it may be due to want of appreciation of the value of ventilation.

F. Meyer was of the opinion that too much blame should not be put upon the insulating varnish. After all, there are different kinds of varnish and different ways of processing it.

A full report of the symposium will appear shortly in the Journal of the Institute of Petroleum.

\section{WHAT IS THE TRUE SHAMROCK?}

\author{
By Dr. HUGH O'NEILL \\ Langlois Herbarium, Catholic University of America, \\ Washington, D.C.
}

$7 \mathrm{HE}$ earliest mention of the word 'shamrock' in English literature as given by the Oxford Dictionary $(8,622-23 ; 1914)$ is in Campion's "History of Ireland", 1571. Other early occurrences of "shamrock' given by the same authority are in the writings of Stonyhurst, 1577 ; Spenser, 1596 ; Holland, 1610; Withers, 1613 and 1633 ; and Moryson, 1617. From these authors it is clear that the plant designated by them 'shamrock' : (1) grew in the woods of Ireland; (2) grew in association with water-cress; (3) had a sour taste; and (4) was commonly eaten by man.

Of all the plants wrongly or rightly identified with the shamrock, only one has all these four char. acteristics. It is the wood-sorrel (wood-sour or woodsower), Oxalis Acetosella L. This plant is certainly 